those authenticated by other national collections of type cultures, or by Australian specialists, and those cultures the authenticity of which cannot be guaranteed. The "Directory" should admirably fulfil its function of informing scientific workers in Australia and in neighbouring countries of the biological material that is readily available to them, and of advertising to men of science elsewhere the extent of Australian collections.

Kodaikanal Observatory during the Past Fifty Years

A sURver of the work of the Kodaikanal Observatory during the past fifty years, from the days of Prof. C. Michie Smith, the first director, up to the present time, is contained in a small booklet entitled "Kodaikanal Observatory 1901-51", issued by the Indian Meteorological Office (pp. $44+12$ plates. Delhi : Manager of Publications, 1952 ; 1 rupee). A considerable amount of the publication is devoted to an account of the work of Evershed, who became director in 1911 after four years as assistant director, and of Royds, who joined as assistant director in the year in which Evershed became director. It is pointed out that the period of sixteen years that Evershed spent at Kodaikanal was marked by great activity, and his and Royds's researches during this time brought Kodaikanal to the front rank among astrophysical observatories. Besides a brief historical outline of the establishment and development of the Solar Physics Observatory at Kodaikanal in 1899, which was derived from the Madras Observatory started in 1792 by the East India Company, the publication describes the instrumental equipment and observational work carried out by the sixteen instruments and five different spectrographs. The account of the work includes sections on the following subjects, among others : discovery of radial motion in sunspots; memoirs on sunspot spectra and prominences; sun-arc displacements-pressure in the reversing layer; Venus spectra; spectroscopic studies ; studies on sunspots and prominences ; study of $\mathrm{H} \alpha$ dark markings ; and prominences and radiation pressure. Supplies of photoheliograms have been sent to the Royal Greenwich Observatory almost from the beginning, and since 1906 exchanges of spectroheliograms have been made with the Solar Physics Observatory, Cambridge. Future developments depend on the financial aid which can be obtained, as contributions in practical and observational work are handicapped from lack of instrumental equipment. As one instance, a really large solar spectrograph with an adequately powerful cœlostat and other accessories, and a Lyot coronagraph are badly needed. Although the Government of India appointed a Standing Advisory Board for Astronomy and Astrophysics in 1948, and a meeting was held in April 1949 as a result of which recommendations were made to the Government, very little had been done up to the time of writing. It is to be hoped that the present director, Dr. A. K. Das, will be able to secure the necessary funds to maintain and even enhance the excellent reputation of this Observatory. Just of late a few items have received attention, and it is very satisfactory to know that the ionospheric laboratory has been completed and the ionosphere recorder installed.

\section{Memoirs of the Society for Endocrinology}

THE Society for Endocrinology is proposing to publish a series of memoirs recording the proceedings of conferences on endocrinological subjects. The first memoir, on the thyroid gland, has recently appeared and contains papers read at a conference held in London on February 25, which was organized by the Society jointly with the Endocrinological Section of the Royal Society of Medicine (pp. 48+ 4 plates; $3 s$. to members, $5 s$. to non-members). The second, which reports a recent conference on the determination of adrenocortical steroids and their metabolites, is in the course of preparation and will be ready shortly. By means of this new venture the Society hopes to effect speedy publication in convenient form, and at a low cost, of papers on topics undergoing rapid change, and, to this end, typolith printing has been used in spite of its æsthetic shortcomings. That the Society has been successful in its main object of rapid publication is apparent from the fact that the memoir on the thyroid gland has appeared only four months after the conference, a notable achievement under present conditions. The memoirs can be obtained by non-members of the Society through any bookseller or direct from Pitmans Press, Parker Street, London, W.C.2.

\section{Medical Research Council : New Members}

By an Order of the Committee of Privy Council for Medical Research, made after consultation with the Medical Research Council and with the president of the Royal Society, Prof. Robert Platt, professor of medicine in the University of Manchester, and Prof. Edward T. C. Spooner, professor of bacteriology and immunology in the London School of Hygiene and Tropical Medicine, have been appointed to be members of the Medical Research Council as from October $1,1953$.

\section{Welded Steel Structures}

A JoINT committee appointed by the Ministry of Works, the Institution of Civil Engineers and the Institution of Structural Engineers, with the support of the Admiralty, War Office, Ministry of Supply, Ministry of Transport and Department of Scientific and Industrial Research, is organizing a conference, the purpose of which is to review present knowledge and outstanding problems in the design, fabrication and erection of welded steel structures. The conference will be held at the Institution of Civil Engineers, Great George Street, London, S.W.1, during November 23-27. Eleven topics have been chosen for discussion, for each of which a special review paper has been prepared; the papers will be circulated beforehand so that most of the time at the conference can be used for discussion. The conference is open to all interested in the subject. Application forms for membership and all further information can be obtained from the Joint Honorary Secretaries, Conference on Welded Structures, Institution of Civil Engineers, Great George Street, London, S.W.1.

\section{Shell Petroleum Co. Awards}

Postgraduate scholarship awards have been made by the Shell Petroleum Co., Ltd., to the following overseas students to enable them to work in British universities: E. A. Parkes, of the University of Tasmania (London), and A. D. Buckingham, of the University of Sydney. (Cambridge); M. H. Panckhurst, of Canterbury University College, N.Z. (Oxford), and J. H. Percy, of Auckland University College (Cambridge); M. J. Stephen, of the University of the Witwatersrand (Oxford), and W. A. Little, of Rhodes University College (Glasgow). 